\title{
DELAMINATION ASSESSMENT DURING MACHINING OF LAMINATED POLYMER NANOCOMPOSITE
}

\author{
Jogendra Kumar, Rajesh Kumar Verma \\ Materials and Morphology Laboratory, Department of Mechanical Engineering, \\ Madan Mohan Malviya University of Technology, Gorakhpur-273010, India \\ Corresponding author: Rajesh Kumar Verma, rkvme@mmmut.ac.in
}

\begin{abstract}
Nanomaterials are gaining extensive application in the manufacturing sector due to favorable properties. Its rapid growth in highly sensitive, robust, and lightweight sensors and biomedical components has attracted considerable attention worldwide. Nanomaterial uses with fiber-reinforced polymeric material have increased significantly. In order to manufacture structural components in a near-net shape, laminated nanocomposite machining is required. Due to the need for product assembly in mechanical structures, Milling is the primarily machining process in the manufacturing industry to create slots, channels, etc. The present work optimized the process variables affecting the Milling process by adopting the minimize criterion to control the delamination factor using the Taguchi method. The process parameters include cutting speed, feed, depth of cut, and filler material Graphene Oxide. The optimized conditions were found as cutting speed $\left(V_{c}\right) 37.12 \mathrm{~m} / \mathrm{min}$, spindle feed $(F) 80$ $\mathrm{mm} / \mathrm{min}$, depth of cut $(D) 0.5 \mathrm{~mm}$ and filler material Graphene Oxide $(G) 1$ wt.\%. The percentage contribution of the process parameter on the delamination factor $\left(F_{d}\right)$ was determined using the Analysis of Variance (ANOVA) method, and it has been found the feed rate $(62.60 \%)$ is the most influencing factor. The delamination factor obtained in the confirmatory experiments carried out under optimized conditions was found lower than the Taguchi design test runs. The findings indicate that process parameter optimization under the given set of experimental conditions is effective for a manufacturing environment.
\end{abstract}

Key words: Delamination factor, Carbon fiber, Taguchi approach, graphene oxide.

\section{INTRODUCTION}

Research work focused on carbon nano-reinforced materials that exhibit better properties compared to the macro filler reinforced polymers materials from past decades. Carbon allotrope like Graphene Oxide Graphene nanoplates, reduce Graphene oxide, Carbon nanotube, and carbon nano onions [1-3], have a dominant application in aerospace industries, automotive sector and construction field. By combining polymer matrix multifaceted carbon nanotubes with polymer matrix multifaceted carbon nanotubes. Most of the studies focussed on the fiber/polymer composites. Hence, the supplement of carbon nanomaterial into the fiber-reinforced polymers could be useful for the manufacturing sector. In this series, Kumar and Singh [4] successfully improved the laminates' inter-laminar shear strength and bending strength in their experimental study. They found that with this strategy, bending strength and inter-laminar shear resistance enhanced by about $24 \%$ and $28 \%$, respectively. The results demonstrated that the surface roughness improved with $1.5 \mathrm{wt} \%$ of the multiwalled carbon nanotube. Graphene oxide consists of a high aspect ratio, surface area, and high strengthening of mechanical properties among the various nanomaterial. Jiang et al. [5] accomplished an electrochemical synthesis technique to prepare a CFs graphene reinforcement composite and prepared another graphene-coated sample onto the CFs. They concluded that the result enhanced mechanical strength by $59.4 \%$ and $12.8 \%$. Coated graphene material onto the CFs using the simplest hand layup method and showed enhanced engineering properties. The composite strength increased by $52 \%$, accompanied by renovated electrical conductivity. In recent days, carbon fibers have played an important role in hybrid composite fabrication and nanomaterials. Hence a study related to the machining of laminated hybrid nanocomposite in the recent trend of research work. Machining of nanocomposite materials is a challenging task for manufacturing industries such as assembling automobile structures, batteries, spacecraft, Turbine, etc. Various challenging issues addressed by manufacturers during laminated polymer nanocomposite machining include circularity error, roughness, burr, fiber pull, matrix delamination, etc. [6-8]. The uncontrolled process parameters of this machining enriched with the complexity of materials, tool geometry, environment condition beyond the 
specified criteria lead to serious damages and result in severe material failure. Thus, the exploration of the Milling process of nanocomposite demands highly durable, cost-effective, and productive to avoid failure of the engineering component. Several investigations are carried out considering parameters cutting speed, feed, depth of cut, tool geometry, tool materials, and tool coating for delamination-induced Milling operation. However, these methods endure from several setbacks in the form of nanomaterials laminated machining. Nanomaterial weight $\%$ is observed as a process constraint to the control delamination factor while Milling process [9, 10]. The aspect of delamination has a major influence on the performance and efficiency of components [11]. Several eminent academics investigated various methods and approaches for controlling the delamination factor. It was also correlated to other factors like tool wear and interface temperature when it comes to cutting performance $[12,13]$. The traditional optimization outcomes of altering one parameter while holding the other variables fixed are considered comprehensive and costly. However, the computational development of research procedures makes the optimization of many operating variables easier and equally effective. Evolutionary functioning is a commonly used test design tool, Taguchi method [14-16] and Response surface methodology [17, 18]. The Taguchi array is a valuable experimental pattern that reduces the trial run in a mathematically balanced way. It is a highly recommended experimental design method in manufacturing, multicriteria assessment, decision science, and other areas. This approach has been applied to improve machining processes in a variety of fields. Therefore, the current work investigates the Milling process of G/CF polymer nanocomposite optimized using the Taguchi method. Asjadi et al [19] investigated the impact of several controllable Milling parameters (table frequency, feed/tooth, and cutting depth) on the MRR and roughness in a CNC Milling machine process. Multi-criteria decision-making (MCDM) techniques are used to determine the best machining condition for a CNC Milling machine. Nine experiments were performed on machine parameters according to the standard $\mathrm{L}_{9}$ orthogonal array of Taguchi. Multi-response optimization was subsequently carried out in the optimal setting. However, the drilling of polymer nanocomposite has been investigated by various eminent scholars. Hossein Heidarya et al. [10] investigated the thrust force, delamination, and residual flexural strength of woven E-glass epoxy fiber composites modified by multiwall nanotubes. The feed rate, spindle speed, drill diameter, and carbon nanotube weight percent were considered as process parameters for the experiment. Experiments were carried out using the
Taguchi technique. Finally, Grey relational analysis (GRA) was used to optimize the various performance features of the process parameter. They revealed that feed rate, followed by spindle speed, has the greatest impact on thrust force and delamination factor. Quan et al. [20] examined the effects of drill speed and feed and the geometry of the drilling hole on delamination at the drill hole using an infiltration method with gold chloride solution. The findings found that the closer to the entry or exit of the hole, the more damaged. Xin Wang et al. [21] used a series of standard drill tool (carbide drill and high-speed steel) performed tests on GFRP, CFRP and printed circuit board. As the drill axial feed increased, there was a constant reduction in the thrust force. Experimental findings indicate that the vibration drilling thrust is lower than that of traditional drilling and claimed that the vibration of drilling technique is optimal to produce micro-holes on fiber reinforced polymer composites. From literature work very few studies have been found in the area of nano materials and hybridization of laminated nanocomposite. In the current work, an effort is made to fabricate a laminated nanocomposite with the low (reduced) delamination behavior under Milling test. Microscope image processing methods measured the inductive delamination. Signal to noise ratio for the analysis of the findings obtained in this work with the aim of reducing the delamination effect for graphene-carbon fiber reinforced polymer (GCFRP) nanocomposites Milling as an modified material for industrial use.

\section{MATERIALS AND METHOD}

\subsection{Development of G-CFRP nanocomposite material}

In sample fabrication, Graphene Oxide with a high impurity (Carbon purity $>99$ ) was used. 400 grams per square meter (GSM) woven $\mathrm{CF}$ and thermoset epoxy 520, hardener-D of the laminated polymer nanocomposites. Laminated nanocomposite G-CFRP were prepared by hand layup technique with considering appropriate quantities weight percentage of Graphene oxide, epoxy and 18 layers of Carbon fiber. The sonicate solutions with different weight $\%$ $(1,2$ and $3 \%)$ of Graphene oxide concentrated were modified epoxy. The prepared sample $(100 \times 100 \times 10$ $\mathrm{mm})$ was prepared for the machining process. Machining (Milling) studies were carried out on a computerized numerical control vertical setup with the TiAlN cutter tool.

\subsection{Delamination factor analysis}

The computerized tomography industrial equipment microscope (Model No. ZSM3780 T2) uses analytical software ULTRA-CMOS5100 to evaluate delamination, as displayed in Figure 1. The control 
process constraints and their operating range are listed in Table 1. For the computerized microscopic procedure, each sample was imaged with three slots for one graph (Figure 2). The Milling delamination factor $\left(F_{d}\right)$ was employed to characterize machined specimens' delamination region (Milling slot). Fd is described as the ratio of the maximum damage slot length of the machined zone to the nominal slot diameter. The following expression is used to compute the Milling induced delamination factor.

$$
\text { Delamination factor }\left(F_{d}\right)=\frac{\left(W_{\max }\right)}{(W)}
$$

where, $\mathrm{W}_{\max }=$ Maximum damage slot width and $\mathrm{W}=$ Nominal damage slot width

Table 1. List of controllable parameters and range of level

\begin{tabular}{|c|c|c|c|c|}
\hline Parameters & $\begin{array}{c}\text { Nomenclature/ } \\
\text { unit }\end{array}$ & $\begin{array}{c}\text { Level } \\
1\end{array}$ & $\begin{array}{c}\text { Level } \\
2\end{array}$ & $\begin{array}{c}\text { Level } \\
3\end{array}$ \\
\hline Cutting Speed & $V_{c}(\mathrm{~m} / \mathrm{min})$ & 12.56 & 25.12 & 37.68 \\
\hline Feed & $\mathrm{F}(\mathrm{mm} / \mathrm{min})$ & 80 & 160 & 240 \\
\hline Depth of cut & $\mathrm{D}(\mathrm{mm})$ & 0.5 & 1 & 1.5 \\
\hline $\begin{array}{c}\text { Wt.\% } \\
\text { Graphene }\end{array}$ & $G(\mathrm{wt} . \%)$ & 1 & 2 & 3 \\
\hline
\end{tabular}

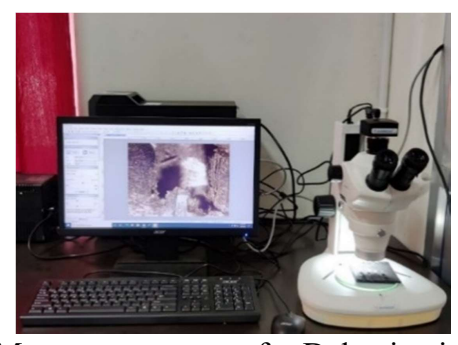

Fig. 1. Measurement setup for Delamination factor
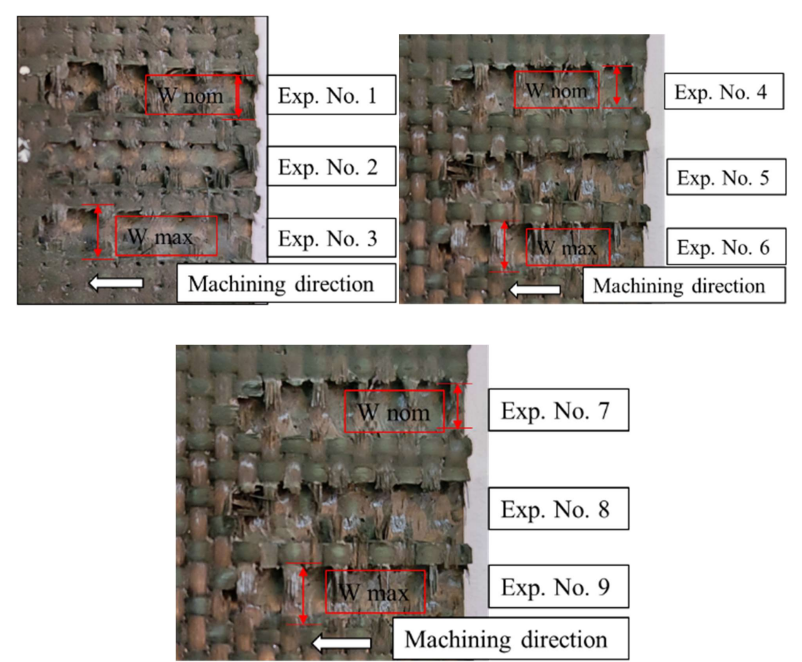

Fig. 2. Sample (1-3 wt.\%) for delamination factor assessment

\subsection{Methodology: Taguchi approach}

Taguchi method is a statistical technique for multi- objective optimization that requires minimal trials to find the desired solution. The approach to assessing the impact of variables on the responses of parameters and their optimal status is easy and systematic. Traditional optimal techniques that involve changing one variable while remaining the others constant are frequently seen to be complicated and expensive. However, the experimental method of design gives a more comfortable and effective method to enrich various operating variable quantities. The evolutionary operation is one of the most commonly used experimental design procedures using the Taguchi method [14, 15, 22] and Response surface methodology [17, 18, 23]. Asghar et. al. [24] conducted a comparison study of two alternative designs. However, practical findings achieved under optimum settings (Taguchi technique) and Central composite design (CCD) were near predicted values. They found that optimizing the Taguchi method's operating parameters is suitable and economical and can be used as a substitute for central composite design. Taguchi methods have been used for optimization in various fields of the machining process. Myers et al [25] analyzed a comparative study between Taguchi and CCD for a case study and found Taguchi produced a positive impact and quality enhancement with statical over CCD. Therefore, the current work investigates the Milling process of $\mathrm{G} / \mathrm{CF}$ polymer nanocomposite optimized using the Taguchi method. For research, Taguchi method $L_{9}$ (nine experiment Table 2) uses an orthogonal array (OA). The OA design has nine experiments that can display different combinations of factor responses. The performance of the orthogonal arrays is optimized rather than the responses themselves, reducing variation in processes. This function distinguishes the Taguchi approach from traditional statistical techniques.

\subsection{Methodology: ANOVA approach}

It is observed as a main criterion for the mathematical function estimation, analysis of variance (ANOVA) models is used as assessment process responses. ANOVA is used to analyze experimental responses for estimating the contribution of each factor and significance level. The correlation among outcome (responses) and one or more independent variables is used to research and model.

Table 2. $L_{9}$-Taguchi design and observed $F_{d}$

\begin{tabular}{|c|c|c|c|c|c|c|}
\hline \multirow[b]{2}{*}{$\begin{array}{l}\text { Exp. } \\
\text { No. }\end{array}$} & \multicolumn{4}{|c|}{ Process Parameters } & \multicolumn{2}{|c|}{ Response } \\
\hline & $\begin{array}{c}V_{c} \\
(\mathrm{~m} / \mathrm{min})\end{array}$ & $\begin{array}{c}F \\
(\mathrm{~mm} / \mathrm{min})\end{array}$ & $\begin{array}{c}D \\
(\mathrm{~mm})\end{array}$ & $\begin{array}{c}G \\
\text { (Wt.\%) }\end{array}$ & $\left(F_{d}\right)$ & $\begin{array}{l}\mathrm{S} / \mathrm{N} \\
\text { ratio } \\
(\mathrm{dB})\end{array}$ \\
\hline 1 & 12.56 & 80 & 0.5 & 1 & 1.19 & $\begin{array}{c}- \\
1.510\end{array}$ \\
\hline 2 & 12.56 & 160 & 1 & 2 & 1.61 & ${ }^{-} \cdot \overline{136}$ \\
\hline
\end{tabular}




\begin{tabular}{|c|c|c|c|c|c|c|}
\hline 3 & 12.56 & 240 & 1.5 & 3 & 1.86 & $\begin{array}{c}- \\
5.390\end{array}$ \\
\hline 4 & 25.12 & 80 & 1 & 3 & 1.52 & $\begin{array}{c}- \\
3.636\end{array}$ \\
\hline 5 & 25.12 & 160 & 1.5 & 1 & 1.36 & $\begin{array}{c}- \\
2.670\end{array}$ \\
\hline 6 & 25.12 & 240 & 0.5 & 2 & 1.79 & $\begin{array}{c}- \\
5.057\end{array}$ \\
\hline 7 & 37.68 & 80 & 1.5 & 2 & 1.28 & $\begin{array}{c}- \\
2.144\end{array}$ \\
\hline 8 & 37.68 & 160 & 0.5 & 3 & 1.31 & $\begin{array}{c}- \\
2.345\end{array}$ \\
\hline 9 & 37.68 & 240 & 1 & 1 & 1.63 & $\begin{array}{c}- \\
4.243\end{array}$ \\
\hline
\end{tabular}

\section{RESULT AND DISCUSSION}

\subsection{Contribution of process parameters: Analysis of variance test}

Table 3 displays the Delamination factor ANOVA results. As shown in the table, feed rate contributes most to the delamination factor, contributing with $62.60 \%$, followed by filler content at $9.79 \%$, cutting pace at $7.28 \%$, and depth of cut at $1.66 \%$. Moreover, Davim and Reis [26] similarly found feed rate main important factor (influence $83.9 \%$ ) during the CFRP composite Milling process. High feed rate values induced a higher delamination effect and depth of cut shows a very less significant effect in the composite machining process $[27,28]$. ANOVA test used to check the adequacy of the developed model and the significance of each factor. Taguchi methodology developed the model after the testing with ANOVA. This shows the factors which is non-significant factors. A value of Prob $>\mathrm{f}$ higher than 0.05 indicated that the factor was non-significant.

Table 3. ANOVA for delamination factor $\left(F_{d}\right)$

\begin{tabular}{|c|c|c|c|c|c|}
\hline Source & DF & Seq SS & Contribution & F-Value & P-Value \\
\hline$V_{c}$ & 1 & 0.032267 & $7.28 \%$ & 1.56 & 0.280 \\
\hline$F$ & 1 & 0.277350 & $62.60 \%$ & 13.41 & 0.022 \\
\hline$D$ & 1 & 0.007350 & $1.66 \%$ & 0.36 & 0.583 \\
\hline$G \%$ & 1 & 0.043350 & $9.79 \%$ & 2.10 & 0.221 \\
\hline Error & 4 & 0.082706 & $18.67 \%$ & & \\
\hline Total & 8 & 0.443022 & $100.00 \%$ & & \\
\hline
\end{tabular}

Regression equation

$$
F d=0.982+0.002687 F
$$

\subsection{Optimization of process parameters to suppress Delamination factor $(\mathbf{F d})$}

Deciding on the 'optimum condition' for the Milling process having a minimum delamination factor is quite difficult. The variety of applications may contain different requirements in their use. Each application requires a certain degree of 'acceptance'

based on geometrical precision. Figure 3 shows the main effect plot of the optimal Milling outcomes (geometrical accuracy) supported by appropriate levels of machining slots. It shows that the 'optimal' Milling conditions were $37.68 \mathrm{~m} / \mathrm{min}$ cutting speed, $80 \mathrm{~mm} / \mathrm{min}$ feed rate, $0.5 \mathrm{~mm}$ depth of cut, and $1 \%$ nano content. The optimum parameter setting for lower delamination factor (1.04) assessment values. Large material flow with the cut fibers was observed during machining at lower cutting speeds, resulting in low efficiency. The chips are mainly of the less deformed matrix at medium cutting speed and therefore, maximum cutting speed is preferable to desirable output [27]. As a result, shearing of the material becomes an elementary phenomenon during the machining process as the cutting speed increases. The higher cutting force is caused by the fact that more material is cut every revolution of the workpiece, which necessitates a greater quantity of energy, leading to a larger cutting force [29]. Deformation of the work material becomes more accessible with a higher cutting speed, and surface roughness is reduced in general. In this study, a lower delamination factor was reported with increasing speed, which could have been due to the work material's simple deformation. The following merits spread over to high-speed cutting: a low bending level for the cutting tool that occurs by reduction of the cutting force, flat chip discharges, while the chip discharge rate surpasses the cutting speed, and uncut fiber yarn burrs are reduced $[30,31]$. With an increased feed rate, the cutting force increases regardless of the Milling condition [29]. In the machining of all composite materials, increasing the feed rate directly increases the surface roughness [32]. It is feasible to find a better surface finish using a higher cutting velocity and a lower feed rate [33]. Furthermore, the research reveals that as the feed rate increases, the $F_{d}$ increases. The results of fiber and resin interfacial debonding and a low resin solidification at high temperatures. This leads to a poor resin-supporting function for carbon fibers. When the temperature of the machined surface or surface layer reaches that of the polymer matrix, epoxy degradation occurs, which results in poor machinability. As a result of the fibers' inability to obtain adequate support from the matrix resin, the machining efficiency of polymer is poor [34]. However, it decreases for filler-loaded samples due to improved epoxy laminate mechanical properties [35]. CNTs have been added to the epoxy, which has led to a more consistent surface finish in doped CFRPs without extensive fiber breakings [36]. The nanomaterial raises the contact surface between the reinforcement and the matrix because of its high aspect ratio, resulting in improved stress distribution and strength properties [9]. As the intensity of the 
cutting force increases with feed rate could affect the surface roughness. The cutting process penetrates more and cuts more material as the depth of cut increases, resulting in higher cutting force [29]. Higher depth of cut generated maximum surface irregularity in a prior study; the reason could be because increased cutting force and higher tool wear occurred with higher depth of cut, causing the surface to deteriorate. The depth of the cut increases, the deformation of fibers increases, leading to the severe deterioration $[29,37]$. The response table for the input factors' means of significance over the delamination factor is shown in Table 4. It has been found that minimax level $F(0.430)$ is the most effective controllable factor with the highest value. It shows that the feed rate is predominant over the cutting speed of the desired G-CFRP nanocomposite output.

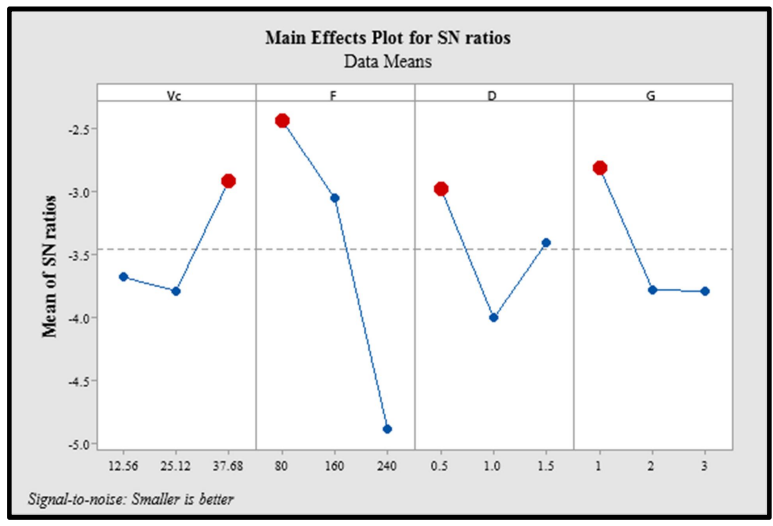

Fig. 3. The influence of parameters Delamination factor

Table 4. Response Table for Means

\begin{tabular}{|c|c|c|c|c|}
\hline Level & $\boldsymbol{V}_{\boldsymbol{c}}$ & $\boldsymbol{F}$ & $\boldsymbol{D}$ & $\boldsymbol{G} \%$ \\
\hline 1 & 1.553 & 1.330 & 1.430 & 1.393 \\
\hline 2 & 1.557 & 1.427 & 1.587 & 1.560 \\
\hline 3 & 1.407 & 1.760 & 1.500 & 1.563 \\
\hline Delta & 0.150 & 0.430 & 0.157 & 0.170 \\
\hline Rank & 4 & 1 & 3 & 2 \\
\hline
\end{tabular}

\subsection{Validation: SEM analysis}

The principal damage mechanism has been described as delamination during Milling. The process that causes delamination is discussed and the crucial factors that lead to the occurrence of delamination. The optimal process variable was used to verify the result for minimal Fd obtained from the Taguchi process. Experimental results data was used to confirm the delamination factor's applicability with high acceptance. The predicted $\left(V_{c}-3, F-1, D-1, G \%-1\right.$ from Table 5) crucial delamination factor is the lowest in Milling. As shown in Figure 4, several of the failures occur at the slot where high feed rates have occurred. If the feed rate is low level, the relative damage is virtually equal to the global damage; this ensures that only a small percentage of the Milling cracks are present within the material volume to be removed. The degree of the delamination zone was revealed by SEM analysis in order to verify the machining quality. A macroscopic assessment of the affected zone's size was carried out at 10x magnification in addition to the studies based on the microstructural analysis.

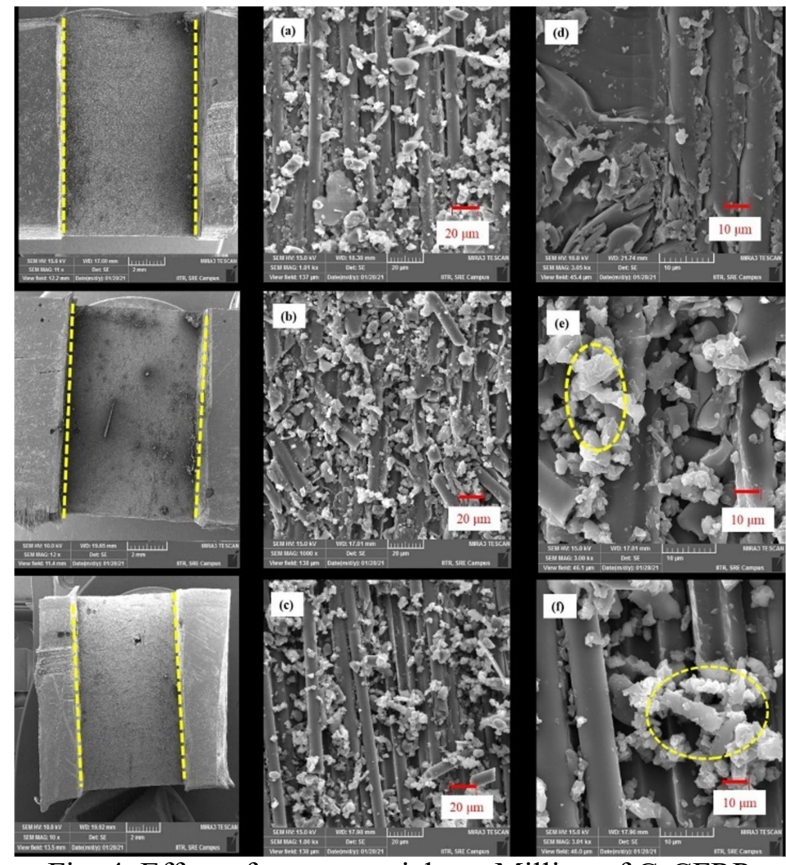

Fig. 4. Effect of nanomaterials on Milling of G-CFRP nanocomposite

Table 5. Confirmatory result

\begin{tabular}{|c|c|c|c|c|}
\hline Response & OA & $\begin{array}{c}\text { Predicted } \\
\text { setting }\end{array}$ & $\begin{array}{c}\text { Confirmation } \\
\text { test }\end{array}$ & $\begin{array}{c}\text { Improvement } \\
\%\end{array}$ \\
\hline & Exp. & $\left(\boldsymbol{V}_{c} \mathbf{- 3}\right.$, & & \\
& No. 7 & $\boldsymbol{F}-\mathbf{1}$, & & \\
& & $\begin{array}{c}\boldsymbol{D}-\mathbf{1}, \\
\boldsymbol{G} \%-\mathbf{1})\end{array}$ & & \\
& & 1.043 & 1.035 & $19.14 \%$ \\
\hline$F_{d}$ & 1.28 & 1.035 & \\
\hline
\end{tabular}

\section{CONCLUSIONS}

This study investigates the damages to the delamination of G-CFRP nanocomposites during Milling. The main emphasis is to optimized delamination factor generation during Milling. According to Taguchi design, it is controlled by the process parameters such as cutting speed, feed rate, and incorporation of weight percentage nanomaterials. For the validation of the established model, confirmatory experiments are performed. The following are the findings found as a result of this research:

-In terms of delamination, the best process parameters for Milling G-CFRP nanocomposites are 
$V_{c}$ level-3, $F$ level-1, $D$ level-1, $G \%$ level-1, which corresponds to a cutting speed of $37.68 \mathrm{~m} / \mathrm{min}$, a feed rate of $80 \mathrm{~mm} / \mathrm{min}$, and a weight percent of nanomaterial of $1 \%$.

-The ANOVA findings indicate that the feed rate is the most crucial factor in altering the delamination extent and it contributes $62.60 \%$.

-The findings of the confirmatory experiments indicate that the appropriate improvement with $19.14 \%$ exists.

-According to SEM analysis, a higher amount $(G \%$ 3) of nanomaterial results in more cracks, pores, and surface holes (due to agglomeration effect), as well as more nonuniform surfaces, while adding optimal level $(G \%-1)$ of nanomaterial to the changed epoxy improves the surface quality, resulting in fewer defects and cracks.

This works shows that graphene significantly enhances the machinability aspect with controlled delamination during Milling. The Taguchi concept was found to be an effective optimization process and its overall performance proved to be well-suited to solve optimization problems in process engineering. In order to solve machining problems for optimization, future work can be extended to study the drilling, turning, and grinding, etc. parameters using the experimental Taguchi design with other nanomaterial epoxy modified in comparative research. The effects of other carbon allotropic nanomaterials can also be studied.

\section{REFERENCES}

1. Kuilla, T.; Bhadra, S.; Yao, D.; Kim, N. H.; Bose, S.; Lee, J. H., (2010). Recent Advances in Graphene Based Polymer Composites. Progress in Polymer Science, 35, 1350-1375.

2. Papageorgiou, D. G.; Kinloch, I. A.; Young, R. J., (2017). Mechanical Properties of Graphene and Graphene-Based Nanocomposites. Progress in Materials Science, 90, 75-127.

3. Kostagiannakopoulou, C.; Tsilimigkra, X.; Sotiriadis, G.; Kostopoulos, V., (2017). Synergy Effect of Carbon Nano-Fillers on the Fracture Toughness of Structural Composites. Composites Part B: Engineering, 129, 18-25.

4. Kumar, D.; Singh, K. K., (2019). Investigation of Delamination and Surface Quality of Machined Holes in Drilling of Multiwalled Carbon Nanotube Doped Epoxy/Carbon Fiber Reinforced Polymer Nanocomposite. Proceedings of the Institution of Mechanical Engineers, Part L: Journal of Materials: Design and Applications, 233, 647-663.

5. Jiang, J.; Yao, X.; Xu, C.; Su, Y.; Zhou, L.; Deng, C., (2017). Influence of Electrochemical Oxidation of Carbon Fiber on the Mechanical Properties of Carbon Fiber/Graphene Oxide/Epoxy Composites.
Composites Part A: Applied Science and Manufacturing, 95, 248-256.

6. He, Y.; Qing, H.; Zhang, S.; Wang, D.; Zhu, S., (2017). The Cutting Force and Defect Analysis in Milling of Carbon Fiber-Reinforced Polymer (CFRP) Composite. International Journal of Advanced Manufacturing Technology, 93, 1829-1842.

7. Stone, R.; Krishnamurthy, K., (1996). A Neural Network Thrust Force Controller to Minimize Delamination during Drilling of Graphite-Epoxy Laminates. International Journal of Machine Tools and Manufacture, 36, 985-1003.

8. Gara, S.; M'hamed, S.; Tsoumarev, O., (2018). Temperature Measurement and Machining Damage in Slotting of Multidirectional CFRP Laminate. Machining Science and Technology, 22, 320-337.

9. Wang, X.; Melly, S. K.; Li, N.; Wang, G. D.; Peng, T.; Li, Y.; Zhao, Q. Di., (2020). Helical Milling Response of Glass Fiber-Reinforced Polymer Composite with Carbon Nanotube Buckypaper Interlayer. Polymers and Polymer Composites, 28, 378-387.

10. Heidary, H.; Karimi, N. Z.; Minak, G.; Zarif, N.; Minak, G.; Karimi, N. Z.; Minak, G., (2018). Investigation on Delamination and Flexural Properties in Drilling of Carbon Nanotube/Polymer Composites. Composite Structures, 201, 112-120.

11. Vasudevan, H.; Deshpande, N.; Rajguru, R.; Mane, S., (2014). Grey Fuzzy Multiobjective Optimization of Process Parameters for CNC Turning of GFRP/Epoxy Composites. Procedia Engineering, 97, 85-94.

12. Haiyan, W.; Xuda, Q.; Hao, L.; Chengzu, R., (2013). Analysis of Cutting Forces in Helical Milling of Carbon Fiber-Reinforced Plastics. Proceedings of the Institution of Mechanical Engineers, Part B: Journal of Engineering Manufacture, 227, 62-74.

13. Ray, D.; Puri, A. B.; Nagahanumaiah., (2019). Investigation on Cutting Forces and Surface Finish in Mechanical Micro Milling of Zr-Based Bulk Metallic Glass. Journal of Advanced Manufacturing Systems, 18, 113-132.

14. Sampath Kumar, T.; Balasivanandha Prabu, S.; Sorna Kumar, T., (2017). Comparative Evaluation of Performances of TiAlN-, AlCrN- and AlCrN/TiAlNCoated Carbide Cutting Tools and Uncoated Carbide Cutting Tools on Turning EN24 Alloy Steel. Journal of Advanced Manufacturing Systems, 16, 237-261.

15. Islam, M. N.; Pramanik, A., (2016). Comparison of Design of Experiments via Traditional and Taguchi Method. Advanced Manufacturing Systems, 15, 151-160.

16. Kulkarni, G. S.; Shivashankar, G. S.; Suresh, R.; Siddeshkumar, N. G., (2020). Optimization of Drilling Parameters of GFRP with Liquid Silicone Rubber and Fine Silica Powder by Taguchi Approach. Silicon, 12, 1651-1666. 
17. Thangarasu, S. K.; Shankar, S.; Mohanraj, T.; Devendran, K., (2020). Tool Wear Prediction in Hard Turning of EN8 Steel Using Cutting Force and Surface Roughness with Artificial Neural Network. Proceedings of the Institution of Mechanical Engineers, Part C: Journal of Mechanical Engineering Science, 234, 329-342. https://doi.org/10.1177/0954406219873932.

18. Hussain, G.; Al-Ghamdi, K. A.; Bijanrostami, K.; Alehashemi, A. J., (2016). Determination of Optimum Process Parameters for Cutting Hole in a RandomlyOriented Glass Fiber Reinforced Epoxy Composite by Milling Process: Maximization of Surface Quality and Cut-Hole Strength. Polymers and Polymer Composites, 24, 81-89. https://doi.org/10.1177/096739111602400201.

19. Moghaddam, M. A.; Kolahan, F., (2016). Application of Orthogonal Array Technique and Particle Swarm Optimization Approach in Surface Roughness Modification When Face Milling AISI1045 Steel Parts. Journal of Industrial Engineering International, 12, 199-209.

20. Quan, Y.; Sun, L., (2010). Investigation on Drilling-Induced Delamination of CFRP with Infiltration Method. Advanced Materials Research, 139, 55-58.

21. Wang, X.; Wang, L. J.; Tao, J. P., (2004). Investigation on Thrust in Vibration Drilling of Fiber-Reinforced Plastics. Journal of Materials Processing Technology, 148, 239-244.

22. Kumar, J.; Verma, R. K., (2021). Multiple Response Optimization in Machining (Milling) of Graphene Oxide-Doped Epoxy/Cfrp Composite Using CoCoSo-PCA: Anovel Hybridization Approach. Journal of Advanced Manufacturing Systems, 20, 423-446.

23. Kumar, J.; Kumar Verma, R.; Debnath, K., (2020). A New Approach to Control the Delamination and Thrust Force during Drilling of Polymer Nanocomposites Reinforced by Graphene Oxide/Carbon Fiber. Composite Structures, 253, 112786.

24. Asghar, A.; Raman, A. A. A.; Daud, W. M. A. W., (2014). A Comparison of Central Composite Design and Taguchi Method for Optimizing Fenton Process. Scientific World Journal, 2014, 869120 (114).

25. Raymond H. Myers, Douglas C. Montgomery, C. M. A.-C., (2016). Response Surface Methodology.

26. Davim, J. P.; Reis, P.; António, C. C., (2004). A Study on Milling of Glass Fiber Reinforced Plastics Manufactured by Hand-Lay up Using Statistical Analysis (ANOVA). Composite Structures, 64, 493500.

https://doi.org/10.1016/j.compstruct.2003.09.054.

27. Palanikumar, K.; Karunamoorthy, L.; Karthikeyan, R., (2006). Multiple Performance
Optimization of Machining Parameters on the Machining of GFRP Composites Using Carbide (K10) Tool. Materials and Manufacturing Processes, 21, 846-852.

28. Thakur, R. K.; Singh, K. K.; Sharma, D., (2019). Modeling and Optimization of Surface Roughness in End Milling of Graphene/Epoxy Nanocomposite. Materials Today: Proceedings, 19, 302-306.

29. Mohammad Shahadath Hossain, N. R. D., (2019). Machinability Study of a Kevlar and Glass Reinforced Polyester. Strojniški vestnik - Journal of Mechanical Engineering, 49, 18-26.

30. Ha, S. J.; Kim, K. B.; Yang, J. K.; Cho, M. W., (2017). Influence of Cutting Temperature on Carbon Fiber-Reinforced Plastic Composites in High-Speed Machining. Journal of Mechanical Science and Technology, 31, 1861-1867.

31. Azmi, A. I.; Lin, R. J. T.; Bhattacharyya, D., (2013). Machinability Study of Glass FibreReinforced Polymer Composites during End Milling. International Journal of Advanced Manufacturing Technology, 64, 247-261.

32. Palanikumar, K., (2012). Analyzing Surface Quality in Machined Composites; Woodhead Publishing Limited.

33. Davim, J. P.; Reis, P., (2005). Damage and Dimensional Precision on Milling Carbon FiberReinforced Plastics Using Design Experiments. Journal of Materials Processing Technology, 160, $160-167$.

34. Wang, H.; Sun, J.; Zhang, D.; Guo, K.; Li, J., (2016). The Effect of Cutting Temperature in Milling of Carbon Fiber Reinforced Polymer Composites. Composites Part A: Applied Science and Manufacturing, 91, 380-387.

35. Saravanakumar, K.; Subramanian, H.; Arumugam, V.; Dhakal, H. N., (2019). Influence of Milled Glass Fillers on the Impact and Compression after Impact Behavior of Glass/Epoxy Composite Laminates. Polymer Testing, 75, 133-141.

36. Papadopoulos, A.; Gkikas, G.; Paipetis, A. S.; Barkoula, N. M., (2016). Effect of CNTs Addition on the Erosive Wear Response of Epoxy Resin and Carbon Fibre Composites. Composites Part A: Applied Science and Manufacturing, 84, 299-307.

37. Wang, F. ji; Zhang, B. yu; Zhao, M.; Cheng, D.; Wang, Z. gang., (2019). Evolution Laws of FiberMatrix Interface Cracks in Machining of Carbon Fiber Reinforced Polymer. International Journal of Advanced Manufacturing Technology, 101, 963-977.

Received: August 5, 2021 / Accepted: December 15, 2021 / Paper available online: December 20, 2021 (C) International Journal of Modern Manufacturing Technologies. 